\title{
RADIAÇÃO ULTRAVIOLETA COMO ALTERNATIVA TECNOLÓGICA PARA DESINFECÇÃO DE EFLUENTE DE INDÚSTRIA DE PAPEL
}

\section{ULTRAVIOLET RADIATION AS A TECHNOLOGICAL ALTERNATIVE FOR PAPER INDUSTRY EFFLUENT DISINFECTION}

\author{
Karoline Mello Millek ${ }^{1}$ \\ Jeanette Beber de Souza ${ }^{2}$ \\ Carlos Magno de Sousa Vidal ${ }^{3}$
}

\begin{abstract}
Resumo
A indústria brasileira de produção de papel destaca-se mundialmente no mercado entre os maiores produtores, mas, aliada a grande produção está a geração de grandes volumes de efluentes líquidos. Uma alternativa de tratamento para estes efluentes é à associação com o efluente sanitário das unidades, que promove vantagens, como a diluição de compostos tóxicos e o fornecimento de nutrientes para o sistema, todavia, também apresenta desvantagens, com destaque para a incorporação de microrganismos patogênicos no efluente final. Desta forma, o tema de investigação aqui tratado, aborda a radiação ultravioleta como alternativa para a desinfecção de efluente da produção de papel em estação de tratamento de efluentes (ETE) que recebe de forma combinada tanto efluente industrial quanto o esgoto doméstico. Foram variados parâmetros como a altura da lâmina líquida e o tempo de exposição à radiação. As eficiências de desinfecção foram avaliadas empregando os microrganismos indicadores de contaminação fecal Escherichia coli e coliformes totais. As diferentes alturas de lâmina líquida estudadas não influenciaram na eficiência da desinfecção, e os resultados obtidos foram plenamente satisfatórios do ponto de vista microbiológico, alcançando remoção de $99,96 \%$ para CT e $100 \%$ para E.coli. Assim obteve-se um efluente final com qualidade de atendimento aos padrões da legislação ambiental vigente e com potencial para reuso.
\end{abstract}

Palavras-chave: efluente papeleiro, desinfecção, coliformes totais e Escherichia coli

\begin{abstract}
Brazilian paper industry stands out in the world being among the largest producers. However, along with the great paper production is the generation of large volume of liquid effluents. One of the treatment alternatives for these effluents is the association with domestic effluent, which promotes the dilution of toxic compounds and the supply of nutrients for the treatment, but it also presents some disadvantages such as the incorporation of pathogenic microorganisms in the final effluent. Therefore, this study evaluates the ultraviolet radiation as an alternative for the disinfection of paper industry effluent in a wastewater treatment plant (WWTP) that receives both industrial wastewater and domestic sewage combined. Parameters such as liquid layer thickness, exposure time to the radiation and disinfection efficiencies were evaluated using the following indicator microorganisms

\footnotetext{
${ }^{1}$ Universidade Estadual do Centro Oeste ( UNICENTRO). Departamento de Engenharia Ambiental. Campus Irati. Rua Professora Maria Rosa Zanon de Almeida. CEP: 84PR505-667, Irati- PR. email: karoline_millek@ hotmail.com

2 Universidade Estadual do Centro Oeste ( UNICENTRO). Departamento de Engenharia Ambiental. Campus Irati. Rua Professora Maria Rosa Zanon de Almeida. CEP: 84505-667. Irati-PR.email: jeanettebeber@yahoo.com.br

3 Universidade Estadual do Centro Oeste ( UNICENTRO). Departamento de Engenharia Ambiental. Campus Irati. Rua Professora Maria Rosa Zanon de Almeida. CEP: 84505-667. Irati..email:cmsvidal@unicentro.br
} 
of fecal contamination: Escherichia coli (E. coli) and total coliforms (TC). The thickness of liquid layers studied did not influence the disinfection efficiency and the obtained results were satisfactory from the microbiological point of view, attaining efficiency removal of $99.96 \%$ and $100 \%$ for TC and E. coli, respectively. As a result, it was obtained a final high-quality effluent, meeting the requirements foreseen by the current environmental laws and showing potential for reuse.

Keywords: paper effluent, disinfection, total coliforms and Escherichia coli.

\section{. INTRODUÇÃO}

A indústria brasileira de celulose e papel figura com um dos segmentos mais desenvolvidos e competitivos do mundo. $\mathrm{O}$ Brasil detém vantagens quando comparado aos outros países, como a elevada extensão territorial e as favoráveis características de solo e clima para o rápido desenvolvimento das espécies, isso, aliado aos avanços tecnológicos nas áreas de genética e manejo florestal que se encontram bem desenvolvidas, colocando o Brasil em destaque nesse setor no mercado mundial. $\mathrm{O}$ País conta com mais de 200 fábricas de papel e/ou celulose, que contribuem significativamente para a economia do país (IBÁ, 2016).

Segundo Relatório Anual do IBÁ (2017), o Brasil possui uma área total de 7,84 milhões de hectares de florestas plantadas, sendo que $34 \%$ pertence às empresas do segmento de papel e celulose, com a maior parte das empresas localizadas próximas ao principal mercado consumidor, nas regiões Sul e Sudeste do País.

Em 2016, a produção brasileira de papel subiu uma posição e ocupou o oitavo lugar no ranking dos maiores produtores, totalizando 10,3 milhões de toneladas de papel produzido (IBÁ, 2017).

Uma vez que o país se encontra com problemas na qualidade da água, torna-se imprescindível o uso de técnicas de tratamento para adequar o efluente de acordo com os padrões de lançamento (HESPANHOL, 2013). Em geral as indústrias de papel e celulose possuem tratamento preliminar, primário e secundário. Todavia, visto que os efluentes gerados possuem elevada carga orgânica e outros contaminantes, torna-se imprescindível a utilização de tratamentos terciários a fim de complementar as demais técnicas usualmente empregadas.

A maioria das fábricas empregam sistemas de tratamento de seus efluentes por lodos ativados e lagoas aeradas, e para melhor desempenho do tratamento biológico podem ser adicionados nutrientes ao sistema, como nitrogênio e fósforo. Uma estratégia adotada para a suplementação destes nutrientes é a mistura dos esgotos sanitários produzidos nas fábricas (NEVES, 2014).

Esta estratégia torna-se interessante, pois além de suplementar o reator biológico com nutrientes necessários ao metabolismo microbiano, possibilita ainda um tratamento mais efetivo para o esgoto doméstico gerado na unidade fabril (JORDÃO e PESSÔA, 2014).

De maneira geral, os efluentes provenientes do processo industrial de produção de papel são isentos de microrganismos patogênicos, entretanto, quando ocorre a mistura com o esgoto doméstico gerado na indústria, estes microrganismos encontram-se presentes.

Neste sentido, a radiação ultravioleta vem como uma tecnologia de tratamento 
terciário visando à desinfecção e subsequente melhoria da qualidade microbiológica do efluente final da ETE (SOUZA et al., 2012).

A desinfecção por radiação ultravioleta é um mecanismo físico, que através da radiação emitida por lâmpadas especiais (germicidas) provoca alterações estruturais no material genético das células, por meio de uma reação fotoquímica capaz de alterar os componentes moleculares essenciais para as funções celulares, causando danos aos ácidos nucleicos (DNA e RNA) e assim, desenvolvendo a inativação microbiana (GONÇALVES et al., 2003; SOUZA et al., 2012; GUO et al., 2011).

Diferentemente dos métodos de desinfecção que utilizam produtos químicos, como, a cloração, com a radiação UV não se adiciona produtos ao efluente, e assim, não se tem um residual de desinfetante no meio. Esta característica constitui uma das principais vantagens da técnica, pois reduz a possibilidade de formação de subprodutos que poderiam estar causando um impacto negativo à biota do corpo receptor (GONÇALVES et al., 2003; SOUZA et al., 2012).

Assim, esta pesquisa busca avaliar a eficiência da radiação UV na inativação de microrganismos indicadores de contaminação fecal presentes em efluente de uma indústria de produção de papel que trata de forma conjunta esgoto industrial e doméstico.

\section{Material e Métodos}

O efluente utilizado neste estudo foi gentilmente fornecido por uma indústria de papel de grande porte localizada no estado do Paraná. A Estação de Tratamento de Efluentes (ETE) da indústria possui uma vazão média de $5000 \mathrm{~m}^{3} \cdot \mathrm{d}^{-1}$; sendo composta em sequência

DOI: http://dx.doi.org/10.24021/raac.v18i1.5840 pelas seguintes unidades de tratamento: calha parshall, grade, caixa de areia, decantador primário, tanques de aeração e decantador secundário.

Foram realizadas 3 campanhas de ensaios de desinfecção com radiação UV com 5 amostras de efluentes coletadas na saída final da referida ETE.

A caracterização do efluente final da ETE (aqui denominado como bruto) foi realizada de acordo com as metodologias estabelecidas pelo Standard Methods for the Examination of Water and Wastewater 22nd edition (APHA, 2012), em que foram analisados os parâmetros: Coliformes totais (UFC/100 mL), Escherichia coli (UFC/100 $\mathrm{mL})$, Absorbância (254 nm), Sólidos Totais (mg.L-1), Sólidos Suspensos Totais (mg.L-1), Turbidez (uT) e pH.

O trabalho experimental de desinfecção utilizando a radiação ultravioleta no tratamento do efluente final de uma indústria de papel foi realizado em escala laboratorial utilizando um reator de bancada com operação em batelada.

O reator UV utilizado na pesquisa foi confeccionado em aço inox composto por uma câmara de irradiação e uma cúpula refletora removível em alumínio que dá suporte a 6 lâmpadas de baixa pressão de vapor de mercúrio com potência nominal de $15 \mathrm{~W}$ da marca Phillips, emersas e distanciadas uniformemente em $2,2 \mathrm{~cm}$ entre si, com acionamento individual por interruptores localizados na parte externa superior do reator. Em todos os ensaios foram mantidas ligadas às seis lâmpadas.

A câmara de desinfecção possui as seguintes dimensões: $45 \mathrm{~cm}$ de comprimento x $40 \mathrm{~cm}$ de largura x $15 \mathrm{~cm}$ de altura. Para a variação da espessura de lâmina líquida utilizou-se um adaptador em aço inox a fim de manter constante a altura das lâmpadas com a superfície do líquido a ser desinfetado, este Vol. 18, N. 1 (2021) 
adaptador possuía as seguintes dimensões: 45 $\mathrm{cm}$ de comprimento x $40 \mathrm{~cm}$ de largura $\mathrm{x} 4 \mathrm{~cm}$ de altura.

Um detalhamento do reator UV empregado nesta pesquisa está apresentado na Figura 1: Em (a) a cúpula refletora, área interna e seu adaptador e em (b) o detalhamento do reator.

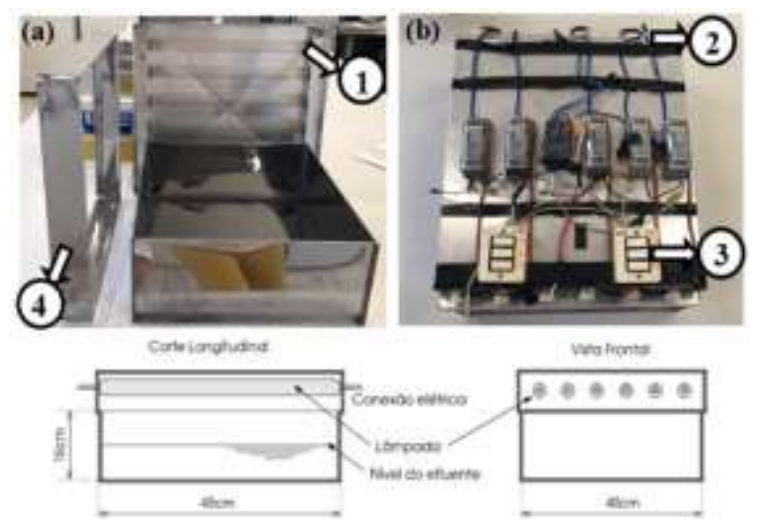

Legenda : (1): Lâmpadas Germicidas UV de 15 W (2): Conexão elétrica; (3): Interruptores individuais para acionamento das lâmpadas;(4): Adaptador para ajustar alturas de lâminas líquidas dentro do reator.

Figura 1. Detalhamento do reator UV utilizado nesta pesquisa.

Nos experimentos com UV a dose é o produto da intensidade de radiação pelo tempo de exposição, conforme a Equação 1.

$\mathrm{D}=\mathrm{I} \cdot \mathrm{t}$

Eq 1

$\mathrm{D}=$ Dose de radiação ultravioleta

(mW.s.cm²);

$\mathrm{I}=$ Intensidade da radiação $\left(\mathrm{mW} . \mathrm{cm}^{2}\right)$;

$\mathrm{t}=$ Tempo de exposição $(\mathrm{s})$.

Entretanto, são duas intensidades de radiação a serem consideradas nesta pesquisa, a quantificação da intensidade da radiação UV emitida pelas lâmpadas e obtenção da intensidade média de radiação no interior do reator (I0) e a intensidade média efetiva DOI: http://dx.doi.org/10.24021/raac.v18i1.5840 denominada de Im, que considera a atenuação ocorrida devido à absorção de radiação pelo meio líquido.

A intensidade de radiação UV emitida pela fonte (I0) foi medida com auxílio de um radiômetro (marca Vilber Loumart) com sensor em comprimento de onda de $254 \mathrm{~nm}$, através de uma malha de 56 pontos equidistantes determinados no fundo do reator.

Para o cálculo de Im deve-se levar em consideração a capacidade de absorção de energia pelos compostos químicos e demais substâncias presentes na água residuária, como por exemplo, os sólidos em suspensão que atenuam a radiação ao longo da massa líquida a ser desinfetada (DANIEL, 2001).

A partir de I0 determinou-se a intensidade média efetiva de radiação (Im) através da Lei de Beer-Lambert (Equação 2) levando-se em consideração a absorbância corrigida a $254 \mathrm{~nm}$ do efluente.

$\operatorname{Im}=\mathrm{I} 0 / \alpha \cdot[1-\mathrm{e}(-\alpha . \mathrm{L})]$

Eq 2

$\mathrm{Im}=$ intensidade média efetiva $\left(\mathrm{mW} \cdot \mathrm{cm}^{-2}\right)$;

$\mathrm{I} 0$ = intensidade média da radiação emitida pela fonte e aplicada à superfície $\left(\mathrm{mW} . \mathrm{cm}^{-2}\right)$; $\alpha=$ coeficiente de absorção $\left(\mathrm{cm}^{-1}\right)$ $\mathrm{L}=$ espessura da lâmina líquida $(\mathrm{cm})$.

Sendo que o coeficiente de absorção é obtido de acordo com a absorbância de acordo com a equação 3:

$$
\begin{aligned}
& \alpha=\mathrm{A} * \ln (10) \quad \text { Eq } 3 \\
& \alpha=2,303 * \mathrm{~A}
\end{aligned}
$$

$\alpha$ : coeficiente de absorbância $\left(\mathrm{cm}^{-1}\right)$;

A: absorbância medida a $254 \mathrm{~nm}\left(\mathrm{~cm}^{-1}\right)$. 
Assim, a dose média efetiva de radiação aplicada no reator pode ser determinada pela Equação 4, correspondendo do produto entre a intensidade ( $\mathrm{Im}$ ) e o tempo de exposição.

$$
\begin{aligned}
& \mathrm{Dm}=\mathrm{Im} . \mathrm{t} . \\
& \mathrm{Eq} 4 \\
& \mathrm{Im}=\text { Dose média efetiva }\left(\mathrm{mWs} . \mathrm{cm}^{-2}\right) ; \\
& \left(\mathrm{mWs} . \mathrm{cm}^{-2}\right) ; \\
& \mathrm{T}=\text { Tempo de exposição }(\mathrm{s})
\end{aligned}
$$

Para a realização dos ensaios de radiação UV o efluente era coletado e inserido dentro do reator UV. Em seguida o reator era preenchido com o efluente em duas alturas diferentes de lâmina líquida (4 e $8 \mathrm{~cm}$ ) dentro do reator e mantido sob agitação por três agitadores magnéticos com espaçamentos equidistantes. Os tempos de exposição utilizados foram de 30, 60 e 90 s para ambas as alturas. Para os ensaios com altura de lâmina líquida de $8 \mathrm{~cm}$ utilizou-se um adaptador em aço inox de $4 \mathrm{~cm}$.

Ao final de cada ensaio o reator era lavado com água destilada e desinfetado com álcool 70\%. Foram realizadas quatro campanhas amostrais para cada altura de lâmina líquida adotada.

Para a realização dos ensaios microbiológicos foi utilizada a técnica da membrana filtrante (APHA, 2012), o meio de cultura utilizado para a quantificação conjunta de Coliformes Totais e Escherichia coli foi o Chromocult ${ }^{\circledR}$ Coliform Agar (Merk).

Os ensaios microbiológicos foram realizados em até 8 horas da obtenção das amostras, nunca excedendo 24 horas, considerando as recomendações de preservação de amostras descritas em APHA (2012).

Para os ensaios, amostras de $100 \mathrm{~mL}$ foram filtradas em membranas estéreis de nitrato de celulose com $0,45 \mu \mathrm{m}$ de porosidade em sistema Manifold para filtração a vácuo com trapp de segurança e filtros autoclaváveis. Em seguida, estas membranas foram colocadas nas placas de Petri e incubadas em estufa a $36 \pm 1^{\circ} \mathrm{C}$ por $24 \pm 1$ hora.

Nesta técnica a interpretação dos resultados se deu pela contagem de colônias a olho nú, as colônias que apresentaram coloração salmão/vermelha são identificadas como CT e as que apresentaram coloração violeta/azul são identificadas como E.coli (Figura 2).

Os resultados foram expressos em Unidade Formadora de Colônia (UFC) por $100 \mathrm{~mL}$.

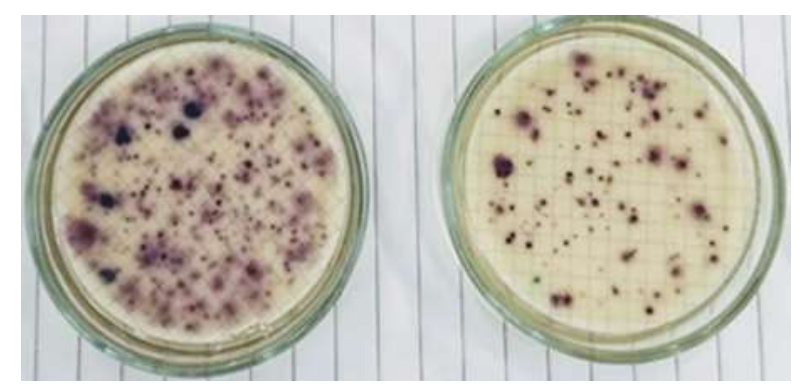

Figura 2. Placas indicando a presença de colônias de CT e E.coli referentes à amostra de efluente bruto nas diluições $10^{-1}$ e $10^{-2}$

A efetividade da inativação microbiana foi calculada pela da Equação 5:

Eficiência $(\log )=\log 10(\mathrm{~N} / \mathrm{N} 0) \quad$ Eq 5

N0 = Número inicial de microrganismos; 
$\mathrm{N}=$ Número de microrganismos remanescentes após desinfecção por radiação UV.

Para todos os dados foram utilizadas três repetições por tratamento e as análises estatísticas foram efetuadas no software livre e gratuito RStudio. Previamente os dados foram checados quanto à gaussianidade dos resíduos e homogeneidade das variâncias pelo teste de Shapiro-Wilk, ao nível de significância de 5\%.

A fim de investigar o comportamento das variáveis categóricas, tempo de exposição (s) e altura de lâmina líquida $(\mathrm{cm})$ na inativação dos microrganismos indicadores de contaminação fecal, CT e E.coli (variáveis dependentes) do efluente, realizou-se um Delineamento Inteiramente Casualizado DIC em esquema fatorial $3 \times 2$, sobre o qual foi aplicada a Análise de Variância (ANOVA).

Como os resultados da ANOVA demonstraram que as interações das variáveis categóricas não foram significativas a $5 \%(\mathrm{p}>$ $0,05)$ de probabilidade, em seguida, aplicouse o Teste de Tukey para o fator tempo de exposição.

\section{RESUltAdOS}

Tabela 1. Intensidades e doses médias efetivas de radiação UV

\begin{tabular}{|c|c|c|c|c|c|c|}
\hline 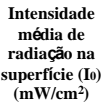 & $\begin{array}{c}\text { Absorbância } \\
\text { (254 nm) }\end{array}$ & $\begin{array}{c}\text { Espessura } \\
\text { da lâmina } \\
\text { líquida }(\mathrm{cm})\end{array}$ & Ensaio & $\begin{array}{c}\text { Tempo de } \\
\text { exposição } \\
\left(\mathrm{s}^{-1}\right)\end{array}$ & 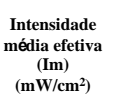 & $\begin{array}{c}\text { Dose média } \\
\text { efetiva } \\
\left(\mathbf{m W s} / \mathbf{c m}^{2}\right)\end{array}$ \\
\hline \multirow{6}{*}{5,77} & \multirow{6}{*}{0,604} & \multirow{3}{*}{4} & \multirow{3}{*}{ ALL4 } & 30 & \multirow{3}{*}{1,03} & 30,9 \\
\hline & & & & 60 & & 61,8 \\
\hline & & & & 90 & & 92,7 \\
\hline & & \multirow{3}{*}{8} & \multirow{3}{*}{ ALL8 } & 30 & \multirow{3}{*}{0,51} & 15,3 \\
\hline & & & & 60 & & 30,6 \\
\hline & & & & 90 & & 45,9 \\
\hline
\end{tabular}

NOTA: In: Intensidade média emitida pela fonte na superfície sem levar em consideração a atenuação (lei de BeerLambert); Im: Intensidade média efetiva levando em consideração a atenuação., ALL: altura de lâmina líquida de 4 e $8 \mathrm{~cm}$.

Tabela 2. Resultados das análises dos parâmetros utilizados na caracterização do efluente bruto

\begin{tabular}{cc}
\hline PARÂMETROS & $\begin{array}{c}\text { MÉDIA } \pm \text { DESVIO } \\
\text { PADRÃO }\end{array}$ \\
\hline Coliformes totais $(\mathrm{UFC} / 100 \mathrm{~mL})$ & $8,05 \mathrm{E}+03 \pm 3,43 \mathrm{E}+03$ \\
Escherichia coli $(\mathrm{UFC} / 100 \mathrm{~mL})$ & $4,40 \mathrm{E}+02 \pm 6,92 \mathrm{E}+02$ \\
Absorbância $(254 \mathrm{~nm})$ & $0,604 \pm 0,06$ \\
Sólidos totais $\left(\mathrm{mg} \cdot \mathrm{L}^{-1}\right)$ & $391,5 \pm 40,0$ \\
Sólidos suspensos totais $\left(\mathrm{mg} \cdot \mathrm{L}^{-1}\right)$ & $1,65 \pm 1,06$ \\
Turbidez $(\mathrm{uT})$ & $5,12 \pm 1,13$ \\
$\mathrm{pH}$ & $7,39 \pm 0,36$ \\
\hline
\end{tabular}

Tabela 3. Inativação dos microrganismos indicadores no efluente bruto nas diferentes condições operacionais estudadas 


\begin{tabular}{|c|c|c|c|c|c|c|}
\hline \multirow{2}{*}{ Ensaio } & \multirow{2}{*}{$\underset{\text { (cm) }}{\text { Esp ALL }}$} & \multirow{2}{*}{$t(s)$} & \multicolumn{2}{|c|}{ CT (UFC.100mL $\left.\mathrm{m}^{-1}\right)$} & \multicolumn{2}{|c|}{ E. coli $\left(\mathrm{UFC} .100 \mathrm{~mL}^{-1}\right)$} \\
\hline & & & N/No & Inativação & N/No & Inativação \\
\hline \multirow{6}{*}{1} & \multirow{3}{*}{4} & 30 & $1,24 \mathrm{E}-02$ & $-1,91$ & $1,33 \mathrm{E}-01$ & $-0,88$ \\
\hline & & 60 & $9,44 \mathrm{E}-03$ & $-2,02$ & $2,33 \mathrm{E}-02$ & $-1,63$ \\
\hline & & 90 & $3,19 \mathrm{E}-03$ & $-2,50$ & 3,33E-03 & $-2,48$ \\
\hline & \multirow{3}{*}{8} & 30 & $8,33 \mathrm{E}-03$ & $-2,08$ & $4,50 \mathrm{E}-02$ & $-1,35$ \\
\hline & & 60 & $7,08 \mathrm{E}-03$ & $-2,15$ & $6,67 \mathrm{E}-03$ & $-2,18$ \\
\hline & & 90 & $2,64 \mathrm{E}-03$ & $-2,58$ & $1,67 \mathrm{E}-03$ & $-2,78$ \\
\hline \multirow{6}{*}{2} & \multirow{3}{*}{4} & 30 & $1,54 \mathrm{E}-01$ & $-0,81$ & $4,14 \mathrm{E}-01$ & $-0,38$ \\
\hline & & 60 & $6,90 \mathrm{E}-02$ & $-1,16$ & $7,14 \mathrm{E}-03$ & $-2,15$ \\
\hline & & 90 & $1,50 \mathrm{E}-03$ & $-2,82$ & $3,57 \mathrm{E}-03$ & $-2,45$ \\
\hline & \multirow{3}{*}{8} & 30 & $8,30 \mathrm{E}-02$ & $-1,08$ & $0,00 \mathrm{E}+00$ & - \\
\hline & & 60 & $5,85 \mathrm{E}-02$ & $-1,23$ & $0,00 \mathrm{E}+00$ & - \\
\hline & & 90 & $4,15 \mathrm{E}-02$ & $-1,38$ & $1,67 \mathrm{E}-03$ & $-2,78$ \\
\hline \multirow{6}{*}{3} & \multirow{3}{*}{4} & 30 & $1,35 \mathrm{E}-02$ & $-1,87$ & $1,00 \mathrm{E}-02$ & $-2,00$ \\
\hline & & 60 & $7,19 \mathrm{E}-03$ & $-2,14$ & $5,00 \mathrm{E}-03$ & $-2,30$ \\
\hline & & 90 & $3,13 \mathrm{E}-04$ & $-3,51$ & $5,00 \mathrm{E}-03$ & $-2,30$ \\
\hline & \multirow{3}{*}{8} & 30 & $1,00 \mathrm{E}-02$ & $-2,00$ & $4,00 \mathrm{E}-01$ & $-0,40$ \\
\hline & & 60 & $9,38 \mathrm{E}-03$ & $-2,03$ & $4,00 \mathrm{E}-02$ & $-1,40$ \\
\hline & & 90 & $5,31 \mathrm{E}-03$ & $-2,27$ & $3,00 \mathrm{E}-02$ & $-1,52$ \\
\hline
\end{tabular}

Tabela 4. Eficiências na inativação dos microrganismos indicadores no efluente bruto nas diferentes condições operacionais investigadas

\begin{tabular}{|c|c|c|c|c|}
\hline \multirow{2}{*}{ Ensaio } & \multirow{2}{*}{$\begin{array}{c}\text { Espessura } \\
\text { da lâmina } \\
\text { líquida } \\
(\mathbf{c m})\end{array}$} & \multirow{2}{*}{$\begin{array}{c}\text { Tempo de } \\
\text { exposição } \\
\text { (s) }\end{array}$} & \multicolumn{2}{|c|}{$\begin{array}{c}\text { Eficiência de Inativação } \\
(\%)\end{array}$} \\
\hline & & & CT & E. coli \\
\hline \multirow{6}{*}{1} & \multirow{3}{*}{4} & 30 & 98,89 & 81,82 \\
\hline & & 60 & 99,16 & 96,82 \\
\hline & & & & \\
\hline & \multirow{3}{*}{8} & 30 & 99,25 & 93,86 \\
\hline & & 60 & 99,37 & 99,09 \\
\hline & & 90 & 99,76 & 99,77 \\
\hline \multirow{6}{*}{2} & \multirow{3}{*}{4} & 30 & 96,17 & 73,64 \\
\hline & & 60 & 98,29 & 99,55 \\
\hline & & 90 & 99,96 & 99,77 \\
\hline & \multirow{3}{*}{8} & 30 & 97,94 & 100,00 \\
\hline & & 60 & 98,55 & 100,00 \\
\hline & & 90 & 98,97 & 99,77 \\
\hline \multirow{6}{*}{3} & \multirow{3}{*}{4} & 30 & 98,39 & 99,55 \\
\hline & & 60 & 99,14 & 99,77 \\
\hline & & 90 & 99,96 & 99,77 \\
\hline & \multirow{3}{*}{8} & 30 & 98,81 & 81,82 \\
\hline & & 60 & 98,88 & 98,18 \\
\hline & & 90 & 99,37 & 98,64 \\
\hline
\end{tabular}

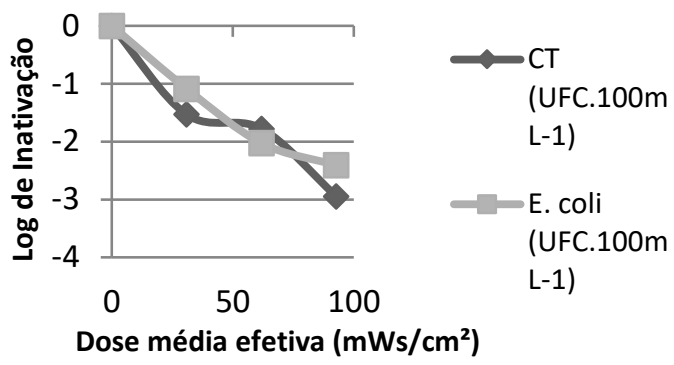

Figura 3 Inativação de CT e E.coli em função da dose de radiação UV empregada para a altura de lâmina líquida de $4 \mathrm{~cm}$

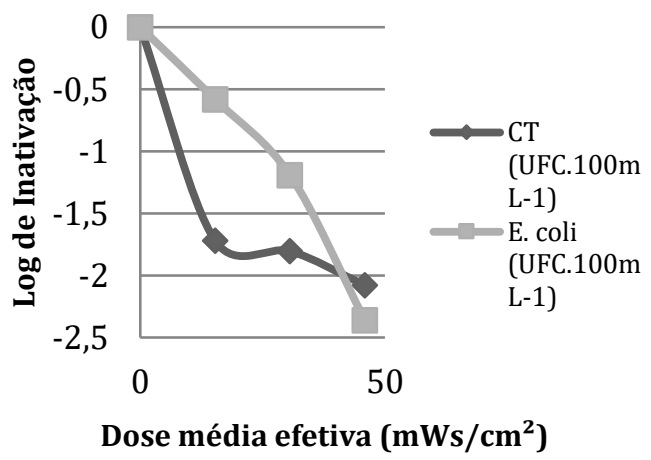

Figura 4. Inativação de CT e E.coli em função da dose de radiação UV empregada para a altura de lâmina líquida de $8 \mathrm{~cm}$

Tabela 5. Resumo da ANOVA em esquema fatorial para CT

\begin{tabular}{lcccc}
\hline \multicolumn{1}{c}{ Causas da variação } & $\begin{array}{c}\text { Graus de } \\
\text { liberdade }\end{array}$ & $\begin{array}{c}\text { Quadrados } \\
\text { médios }\end{array}$ & F & P \\
\hline Altura de lâmina líquida (cm) & 1 & 533,60 & 0,1275 & 0,69845 \\
Tempo de exposição (s) & 2 & 18554,10 & 5,4763 & $0,02042^{*}$ \\
ALL * tempo & 2 & 4540,70 & 1,3402 & 0,29830 \\
Resíduo & 12 & 3388,10 & & \\
Total & 17 & & & \\
Legenda: * = Significativo a 5\% de probabilidade de erro, pelo teste de F. & &
\end{tabular}

Legenda: $*$ = Significativo a $5 \%$ de probabilidade de erro, pelo teste de F. 
Tabela 6. Resumo da ANOVA em esquema fatorial para E.coli

\begin{tabular}{lcccc}
\hline \multicolumn{1}{c}{ Causas da variação } & $\begin{array}{c}\text { Graus de } \\
\text { liberdade }\end{array}$ & $\begin{array}{c}\text { Quadrados } \\
\text { médios }\end{array}$ & F & P \\
\hline $\begin{array}{l}\text { Altura de lâmina líquida } \\
(\mathrm{cm})\end{array}$ & 1 & 2,945 & 0,3546 & 0,56258 \\
Tempo de exposição (s) & 2 & 37,516 & 4,5176 & $0,03447^{*}$ \\
ALL * tempo & 2 & 2,834 & 0,3412 & 0,71759 \\
Resíduo & 12 & 8,304 & & \\
Total & 17 & & & \\
\hline
\end{tabular}

Legenda: * = Significativo a $5 \%$ de probabilidade de erro, pelo teste de F.

Tabela 7. Teste de Tukey para CT e E. coli considerando o parâmetro tempo de exposição

\begin{tabular}{ccc}
\hline Tempo de exposição (s) & Médias de CT* & Médias de E.coli* $^{*}$ \\
\hline 30 & $141,5 \mathrm{a}$ & $5,878^{* *} \mathrm{a}$ \\
60 & $88,83 \mathrm{ab}$ & $1,8307^{* *} \mathrm{ab}$ \\
90 & $30,33 \mathrm{~b}$ & $1,3106^{* *} \mathrm{~b}$ \\
\hline
\end{tabular}

*Médias seguidas da mesma letra não diferem entre si. ** Gerou-se a partir da extração da raiz quadrada de cada observação.

Tabela 8. Remanescentes de CT e E. coli após os ensaios de desinfecção

\begin{tabular}{|c|c|c|c|c|}
\hline Ensaio & $\begin{array}{l}\text { Espessura da lâmina } \\
\text { líquida (cm) }\end{array}$ & $\begin{array}{c}\text { Tempo de } \\
\text { exposição }\left(\mathrm{s}^{-1}\right)\end{array}$ & CT (UFC. $\left.100 \mathrm{~mL}^{-1}\right)$ & $\begin{array}{c}\text { E. coli } \\
\left(\mathrm{UFC} .100 \mathrm{~mL}^{-1}\right)\end{array}$ \\
\hline \multirow{6}{*}{1} & \multirow{3}{*}{4} & 30 & $8,90 \mathrm{E}+01$ & $8,00 \mathrm{E}+01$ \\
\hline & & 60 & $6,80 \mathrm{E}+01$ & $1,40 \mathrm{E}+01$ \\
\hline & & 90 & $2,30 \mathrm{E}+01$ & $2,00 \mathrm{E}+00$ \\
\hline & \multirow{3}{*}{8} & 30 & $6,00 \mathrm{E}+01$ & $2,70 \mathrm{E}+01$ \\
\hline & & 60 & $5,10 \mathrm{E}+01$ & $4,00 \mathrm{E}+00$ \\
\hline & & 90 & $1,90 \mathrm{E}+01$ & $1,00 \mathrm{E}+00$ \\
\hline \multirow{6}{*}{2} & \multirow{3}{*}{4} & 30 & $3,08 \mathrm{E}+02$ & $1,16 \mathrm{E}+02$ \\
\hline & & 60 & $1,38 \mathrm{E}+02$ & $2,00 \mathrm{E}+00$ \\
\hline & & 90 & $3,00 \mathrm{E}+00$ & $1,00 \mathrm{E}+00$ \\
\hline & \multirow{3}{*}{8} & 30 & $1,66 \mathrm{E}+02$ & $0,00 \mathrm{E}+00$ \\
\hline & & 60 & $1,17 \mathrm{E}+02$ & $0,00 \mathrm{E}+00$ \\
\hline & & 90 & $8,30 \mathrm{E}+01$ & $1,00 \mathrm{E}+00$ \\
\hline \multirow{6}{*}{3} & \multirow{3}{*}{4} & 30 & $1,30 \mathrm{E}+02$ & $2,00 \mathrm{E}+00$ \\
\hline & & 60 & $6,90 \mathrm{E}+01$ & $1,00 \mathrm{E}+00$ \\
\hline & & 90 & $3,00 \mathrm{E}+00$ & $1,00 \mathrm{E}+00$ \\
\hline & \multirow{3}{*}{8} & 30 & $9,60 \mathrm{E}+01$ & $8,00 \mathrm{E}+01$ \\
\hline & & 60 & $9,00 \mathrm{E}+01$ & $8,00 \mathrm{E}+00$ \\
\hline & & 90 & $5,10 \mathrm{E}+01$ & $6,00 \mathrm{E}+00$ \\
\hline
\end{tabular}

Tabela 9. Classes de água de reuso e tratamentos necessários de acordo com NBR $13.969 / 1997$

DOI: http://dx.doi.org/10.24021/raac.v18i1.5840

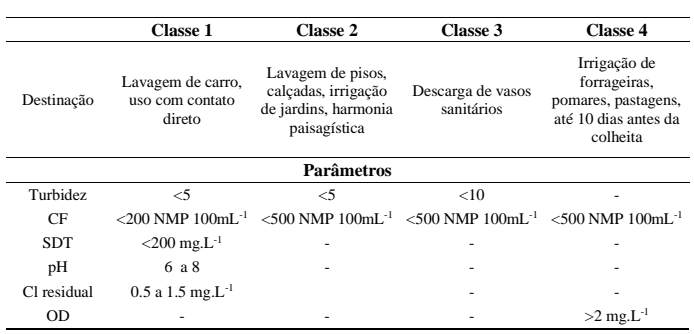

Legenda: $\mathrm{CF}=$ coliformes fecais; $\mathrm{NMP}=$ número mais provável; $\mathrm{SDT}=$ sólidos dissolvidos totais; $\mathrm{Cl}=$ cloro; $\mathrm{OD}=$ oxigênio dissolvido

Tabela 10. Critérios recomendados para reuso agrícola restrito em cada referência considerada

\begin{tabular}{|c|c|c|c|c|c|c|}
\hline & $\begin{array}{l}\text { USEPA } \\
\text { (2012) }\end{array}$ & $\begin{array}{l}\text { OMS } \\
(2006)\end{array}$ & $\begin{array}{l}\text { PROSAB } \\
\text { (2006) }\end{array}$ & $\begin{array}{l}\text { CETESB } \\
(2006)\end{array}$ & $\begin{array}{l}\text { Resolução } \\
\text { COEMA } \\
\text { no }^{\circ} 2 / 2017\end{array}$ & $\begin{array}{c}\text { Resolução } \\
\text { Conjunta } \\
\text { SES/SMA/SSRH } \\
\mathrm{n}^{\circ} 01 / 2017\end{array}$ \\
\hline $\begin{array}{l}\mathrm{CT} \\
(\mathrm{NMP} / 100 \mathrm{~mL})\end{array}$ & $<200^{(2)}$ & $\begin{array}{c}10^{4} \mathrm{a} \\
10^{6(1)(2)}\end{array}$ & $\begin{array}{l}<10^{4} \text { ou } \\
<10^{5(1)}\end{array}$ & $\begin{array}{c}10^{1} \mathrm{a} \\
10^{5}\end{array}$ & $<10^{3}$ & $<200$ \\
\hline $\begin{array}{l}\text { Ovos de } \\
\text { helmintos }\end{array}$ & - & $\begin{array}{c}<1 \\
\text { ovo/L }\end{array}$ & $\begin{array}{c}<1 \\
\text { ovo/L }\end{array}$ & $\begin{array}{c}<1 \\
\text { ovo/L }\end{array}$ & $\begin{array}{c}<1 \\
\text { ovo/L }\end{array}$ & $1 \mathrm{ovo} / \mathrm{L}$ \\
\hline pH & $\begin{array}{l}6.0- \\
9.0\end{array}$ & - & - & - & $6.0-8.5$ & 6.0 a 9.0 \\
\hline $\mathrm{DBO}(\mathrm{mg} / \mathrm{L})$ & $\leq 30$ & - & - & - & - & $\leq 30$ \\
\hline SST (mg/L) & $\leq 30$ & - & - & - & - & $\leq 30$ \\
\hline
\end{tabular}

(1) Varia conforme a técnica de irrigação, tipo de cultura e grupos expostos;

(2) A USEPA utiliza coliformes fecais como critério de indicador patogênico e a OMS E.coli.

\section{DISCUSSÃo}

O conjunto das seis lâmpadas ligadas à intensidade média emitida pela fonte (I0) apresentou uma média de radiação na superfície de $5,77 \pm 1,23$ mWs.cm ${ }^{-2}$ considerando a medida realizada em 56 pontos deno do reator UV.

A partir do valor da absorbância das amostras, foi calculado o coeficiente de absorbância de acordo com a Lei de BeerLambert e em seguida, com as medidas de altura de lâminas líquidas, tempo de exposição, coeficiente de absorbância e o valor da intensidade média emitida pela fonte obtiveram-se os valores de intensidade média efetiva (Im), que leva em consideração a capacidade de absorção da radiação pelas 
substâncias presentes no efluente. Por fim, obteve-se as doses médias efetivas (Dm) para cada tempo de exposição empregado.

A Tabela 1 apresenta os resultados encontrados para intensidade e doses médias efetivas de radiação UV em cada altura de lâmina líquida estudada.

Observa-se na Tabela 1 que as doses médias efetivas decrescem com o aumento da espessura da lâmina líquida.

Os resultados das análises do efluente final da ETE a ser desinfetado por radiação UV são apresentados na Tabela 2, para todos os parâmetros avaliados de caracterização físico-química e microbiológica do efluente.

Fatores como a absorbância, a turbidez e os sólidos suspensos totais apresentam grande interferência na desinfecção por radiação UV. A absorbância está associada a concentração de sólidos suspensos, metais e outros componentes orgânicos e inorgânicos dissolvidos no efluente (METCALF E EDDY, 2003).

Os sólidos suspensos totais (SST) atuam como material de proteção para os microrganismos alvo da desinfecção e absorvem a radiação UV, estando a turbidez relacionada com os SST (METCALF E EDDY, 2003).

O valor da absorbância do efluente encontra-se dentro da faixa dos valores típicos (04 a 0,8 nm) dos parâmetros de dimensionamento de reatores UV com lâmpadas emersas (GONÇALVEZ et al., 2003).

O valor de $1,65 \pm 1,06$ para SST encontra-se abaixo do valor de $30 \mathrm{mg} . \mathrm{L}^{-1}$ admitido pela EPA (1999b) para se trabalhar com radiação UV, já os valores de turbidez e absorbância estão acima dos máximos recomendados, 5 uT (NATURALTEC, 2010) e 0,1 de absorbância em comprimento de onda de $254 \mathrm{~nm}$ (valor usualmente adotado pelos fabricantes de equipamentos de desinfecção por radiação UV) respectivamente.
As concentrações médias iniciais verificadas no efluente bruto para os microrganismos $\mathrm{CT}$ e $E$. coli, foram, respectivamente, $8,05 \mathrm{E}+03 \mathrm{UFC} / 100 \mathrm{~mL}$ e $4,40 \mathrm{E}+02$ UFC/100mL, abaixo das concentrações usuais para esgoto sanitário, devido a sua diluição com o efluente industrial.

A Tabela 3 reúne os resultados obtidos para a concentração dos microrganismos indicadores após a desinfecção por radiação UV para cada ensaio realizado. É notável a variação da densidade de microrganismos em função das amostras.

No ensaio 1 em que o efluente apresentava concentração de SST de 2,4 $\mathrm{mg} . \mathrm{L}^{-1}$, as maiores inativações de CT e E. coli obtidas foram próximas de $3 \log$ para a dose de 45,9 mWs $/ \mathrm{cm}^{2}$ em ALL de 8 cm. Na ALL de 4 cm com dose de $92,7 \mathrm{mWs} / \mathrm{cm}^{2}$ obtevese inativação de aproximadamente 2,5 log. Observa-se elevadas inativações em diferentes condições operacionais , mostrando-se o elevado desempenho da radiação ultravioleta na inativação microbiana, sobretudo para efluentes com baixa concentração de sólidos suspensos totais.

Para o ensaio 2 obteve-se inativação total de E.coli com dose variando de 15,3 a $30,6 \mathrm{mWs} / \mathrm{cm}^{2}$ e para o indicador CT a maior inativação, com aproximadamente 3 unidades logarítmicas ocorreu em dose aplicada de 92,7 $\mathrm{mWs} / \mathrm{cm}^{2}$. Este ensaio foi o mais satisfatório em termos de eficiência de inativação de CT e E.coli, o que está atribuído a melhor qualidade do efluente em relação à presença de sólidos e turbidez: $0,4 \mathrm{mg} . \mathrm{L}^{-1}$ de SST e 3,23 uT, respectivamente.

No ensaio 3 empregando-se dose de radiação UV de $92,7 \mathrm{mWs} / \mathrm{cm}^{2}$ obteve-se os maiores valores de inativação de CT e E.coli, com 3,5 $\log$ e $2,3 \quad \log$ de inativação respectivamente, o que está associado a uma elevada dose de radiação e baixa concentração de sólidos suspensos no efluente. 
A Tabela 4 reúne os resultados obtidos para a eficiência de inativação em termos percentuais para a concentração dos microrganismos indicadores após a desinfecção por radiação UV para cada ensaio realizado.

Para E.coli observou-se uma melhor média de eficiência de remoção, apresentando-se este como um organismo com menor resistência ao efeito da radiação UV, alcançando-se remoção total em duas situações com altura da lâmina líquida igual a $8 \mathrm{~cm}$ em doses de 15,3 e 30,6 mWs.cm².

De maneira geral os coliformes totais apresentaram decaimento contínuo com o aumento da dose de exposição, contudo, a remoção total deste microrganismo não foi alcançada em nenhuma das doses empregadas tendo em vista que são em geral mais resistentes.

Avaliando-se os dados apresentados na Tabela 5 para CT e E.coli os resultados demonstram que as eficiências de redução para a desinfecção UV já no primeiro tempo de contato (30s) foram de até 99,25 e 100\% respectivamente, demonstrando que mesmo em reduzidos tempos de contato é possível obter ótimos resultados.

Para o tempo de contato de 60s obtevese para CT e E.coli as eficiências de inativação de 99,37 e $100 \%$ respectivamente, alcançando-se maiores eficiências de inativação com o aumento do tempo de contato.

No maior tempo de exposição testado neste trabalho para a desinfecção UV (90s) obteve-se $99,96 \%$ de inativação para CT e 99,77\% para E.coli, apesar da tendência do aumento do percentual de inativação à medida em que se aumenta o tempo de contato, para E.coli o mesmo não aconteceu, porém, quando se leva em consideração os valores médios, a premissa se confirma.

Verificou-se também que quando a E.coli foi submetida a uma dose de 45,9 ou de $92,7 \mathrm{mWs} / \mathrm{cm}^{2}$ a eficiência de desinfecção foi

DOI: http://dx.doi.org/10.24021/raac.v18i1.5840 a mesma, ou seja, isso mostrou que para um mesmo tempo de exposição, a variação da altura da lâmina a inativação microbiana foi praticamente a mesma.

$\mathrm{Na}$ Figura 3 são apresentados os resultados médios de inativação dos microrganismos CT e E. coli em função da dose de radiação UV empregada para a altura de lâmina líquida de $4 \mathrm{~cm}$.

Verifica-se na Figura 3 que a desinfecção com radiação UV foi bastante efetiva para CT e E. coli com 90 segundos de exposição (dose média efetiva de 92,7 mWs.cm ${ }^{-2}$ ) sendo possível alcançar a inativação média de 2,94 \pm 0,51 log para CT e 2,41 $\pm 0,09 \log$ para E. coli.

Souza et al. (2012) obteve inativação de aproximadamente 3 unidades logarítmicas para CT com dose de 95,13 mWs.cm-2 aplicadas à efluente de esgoto sanitário proveniente de tratamento biológico. $\mathrm{Na}$ presente pesquisa as doses de radiação UV empregadas encontram-se nesta faixa, observando semelhanças nas unidades logarítmicas de remoção.

De acordo com Lazarova et al. (1999), doses de radiação UV entre 30 a $45 \mathrm{mWs.cm}^{-}$ 2 para efluentes oriundos de tratamento secundário, são suficientes para uma remoção entre 3 a 5 unidades logarítmicas de CT. Estes resultados mostraram semelhanças aos resultados obtidos neste trabalho para ambos os microrganismos indicadores.

Para E.coli no presente ensaio, com 30 segundos de exposição à radiação UV (dose média efetiva de 30,9 mWs. $\mathrm{cm}^{-2}$ ) houve inativação média de 1,09 log. Tal resultado de inativação com base na dose média efetiva foi semelhante ao trabalho de Koivunen e Heinonen-Tanski (2005), onde com doses de radiação de 22 a $38 \mathrm{mWs} . \mathrm{cm}^{-2}$ alcançaram uma inativação de 1,44 para E.coli em efluente sintético.

De um modo geral, foi possível observar o decaimento no número de microrganismos indicadores com o aumento do tempo de exposição à radiação UV, como 
é possível observar nas Figuras 8 e 9 para os ensaios realizados nas duas alturas de lâmina líquida (4 e $8 \mathrm{~cm}$ ).

$\mathrm{Na}$ Figura 4 são apresentados os resultados de inativação dos microrganismos CT e E. coli em função da dose de radiação UV empregada para a altura de lâmina líquida de $8 \mathrm{~cm}$.

Neste ensaio a desinfecção com radiação UV também foi bastante efetiva para CT e E. coli com $90 \mathrm{~s}^{-1}$ de exposição (dose média efetiva de 45,9 mWs.cm ${ }^{-2}$ ) sendo possível alcançar a inativação média de 2,08 \pm 0,62 log para CT e, 2,36 \pm 0,72 log para E.coli.

Para CT com dose média efetiva de 30,6 mWs.cm-2 (60s de exposição) houve inativação média de 1,8_log. Tal resultado de inativação com base na dose média efetiva foi semelhante ao descrito por Hijnen et al. (2006) em seu estudo bibliográfico, onde comenta que para a maioria das bactérias com doses próximas a $20 \mathrm{mWs} . \mathrm{cm}^{-2}$ foram obtidos valores de até 3 unidades logarítmicas de inativação dos microrganismos indicadores de bactérias.

A utilização da radiação UV apresentou-se muito eficiente para E.coli com dose média efetiva de $45,9 \mathrm{mWs} . \mathrm{cm}^{-2}$, onde as cargas bacterianas iniciais eram de $4,40 \times 10^{2} \mathrm{e}$ foram quase totalmente removidas, resultado semelhante ao encontrado por Donaire et al. (2001) em água bruta, que com cargas bacterianas iniciais de $4,10 \times 10^{2}$ e dose média aplicada de $63 \mathrm{mWs} . \mathrm{cm}^{-2}$ atingiu a total remoção da carga bacteriana.

Para ambos microrganismos foi obtido decaimento contínuo com o aumento da dose de exposição, contudo, atribui-se a eficiência do método empregado principalmente no que se refere à baixa concentração de sólidos (SST) no efluente, uma vez que a presença de partículas em suspensão afeta substancialmente a intensidade média efetiva de radiação incidente nos microrganismos, segundo Tchobanoglous et al. (1991) a concentração de SST deve ser menor que 10 mg. $\mathrm{L}^{-1}$.

DOI: http://dx.doi.org/10.24021/raac.v18i1.5840
Guo et al. (2011) para efluente de tratamento secundário obteve inativação média de aproximadamente $3 \log$ para CT, porém, para $E$. coli foi de aproximadamente de $2 \log$ com dose de radiação de 34,47 \pm 11 ,2 $\mathrm{mWs} . \mathrm{cm}^{-2}$. A diferença de inativação em função da mesma dose de radiação UV aplicada pode estar relacionada com a resistência dos microrganismos que variam entre as espécies e até mesmo dentro da mesma espécie (QUEK E HU, 2008).

A fim de corroborar com os resultados acima citados, foi realizada a análise fatorial para os microrganismos indicadores CT e E.coli (Tabela 5 e 6) para determinar também estatisticamente a influência dos fatores tempo de exposição (dose) e altura de lâmina líquida no tratamento por radiação UV no efluente de estudo.

De acordo com os resultados do teste ANOVA, apenas o fator tempo de exposição apresentou significância $(p<0,05)$ tanto para CT quanto para E.coli, ou seja, somente o fator tempo de exposição apresentou influência no processo de desinfecção do efluente.

De acordo com o teste $\mathrm{F}$, as médias do fator altura de lâmina líquida são estatisticamente iguais tanto para CT quanto para E.coli, ou seja, as duas alturas de lâmina líquida testadas (4 e $8 \mathrm{~cm}$ ) não apresentaram diferença nos resultados do tratamento por radiação UV no efluente em estudo. Também se constatou que não há relação entre o fator altura de lâmina líquida e tempo de exposição tanto para CT ( $\mathrm{p}=0,29830)$ quanto para $E$. coli $(p=0,71759)$.

Assim, o teste de Tukey foi aplicado para o fator tempo de exposição para os microrganismos indicadores CT e E. coli (Tabela 7).

Verificou-se por meio do teste de Tukey aplicado que o tempo de exposição de 30 s e o de 90 s diferiram estatisticamente, e que o tempo de exposição de 60s não diferiu estatisticamente quando comparado com o tempo de 30 e de 90 s. Desta forma, sabendose que o tempo de exposição de 90 s foi o que 
apresentou menores médias de concentrações residuais de CT e E.coli e que estas não diferiram estatisticamente das médias obtidas pelo tempo de 60s, pensando em termos de custo-benefício e rapidez do processo, podese concluir que o tempo de 60s se mostrou mais adequado para a desinfecção do efluente em estudo.

Mais do que os valores de eficiência de inativação de CT e E. coli, as densidades finais desses microrganismos, remanescentes dos ensaios de desinfecção com radiação UV e, ainda presentes no efluente tratado, também devem ser considerados e encontram-se apresentadas na Tabela 8 .

Para algumas condições experimentais testadas, a carga bacteriana inicial não foi completamente removida, mas foi significativamente diminuída, como nos ensaios 2 e 3 com altura de lâmina líquida de $4 \mathrm{~cm}$ com tempo de exposição de $90 \mathrm{~s}$ para CT e E.coli, onde o valor médio de $\mathrm{N} 0$ era de $8,05 \times 10^{3} \mathrm{NMP} / 100 \mathrm{~mL}$ e $4,40 \times 10^{2} \mathrm{NMP} / 100$ $\mathrm{mL}$, e foi reduzido para 3,0 NMP/100 mL e para 1,0 NMP/100 mL respectivamente.

Assim, de acordo com o exposto anteriormente e a partir dos dados observados na Tabela 9, verifica-se que este efluente possui grande potencialidade para reuso, de acordo com a NBR 13.969/97 que trata sobre o dimensionamento, construção e operação de tanques sépticos, mais especificamente no seu item 5.6 descreve o reuso local e menciona que "o esgoto tratado em condições de reuso possa ser exportado para além do limite do sistema local para atender à demanda industrial ou outra demanda da área próxima" (Tabela 9).

\footnotetext{
Observa-se que as concentrações remanescentes dos microrganismos indicadores neste trabalho encontram-se abaixo dos valores permitidos pela norma brasileira, assim, com possibilidade de reuso, até mesmo para atividades de uso com contato direto, como por exemplo, a lavagem de veículos.
}

DOI: http://dx.doi.org/10.24021/raac.v18i1.5840
O Brasil ainda não possui regulamentação para o reuso potável (seja direto ou indireto), apesar do reuso potável indireto ser involuntariamente amplamente aplicado, devido as captações de água para abastecimento público ocorrerem em corpos hídricos que receberam o lançamento de esgoto sanitário (doméstico e industriais) à montante.

Hespanhol (1998) apud Tsutiya (2001) comentam que os reuso no âmbito industrial mais comuns são os seguintes: torres de resfriamento, caldeiras, construção civil, irrigação de áreas verdes de instalação industriais, lavagens de pisos e processos industriais. O efluente tratado por desinfecção UV neste trabalho, levando em consideração o quesito microbiológico, poderia ser utilizado como formas de reuso na irrigação paisagística, para fins ornamentais e como água nas torres industriais de refrigeração.

Outra possível utilização para este efluente tratado seria em sistemas de fertirrigação, Smith et al. (1997) e Thacker (1985b) citados por Rezende (2003) estudaram a aplicação de efluente proveniente de fábricas de celulose na silvicultura e demonstram que isso pode se tornar uma opção atrativa para se alcançar um fechamento do circuito para o setor florestal.

Observa-se também que o efluente estudado após o tratamento com radiação UV, no que se refere ao quesito microbiológico, atende aos padrões estabelecidos até mesmo na legislação mais rígida, na categoria para reuso agrícola restrito (Tabela 10), como a USEPA (2012), que os dados se encontram abaixo dos valores permitidos (CF <200 UFC $100 \mathrm{~mL}^{-1}$ ).

\section{ConClusão}

O presente trabalho permitiu avançar no estudo da radiação UV no tratamento terciário de efluente da_indústria de produção de papel, apresentando-se como uma excelente solução para a desinfecção final de 
ETE que trata de forma combinada efluente industrial e doméstico.

As características do efluente foram compatíveis com a aplicação da radiação $\mathrm{UV}_{\overline{\text { }}}$ tendo em vista os baixos valores de sólidos suspensos presentes neste efluentes secundários.

A altura de lâmina liquida de efluente no reator UV não exerceu influência significativa na eficiência da desinfecção, todavia,_os tempos de exposição e doses médias efetivas demonstraram influência na inativação, alcançando-se melhores resultados com 90 segundos de exposição, na dose média efetiva de 92,7 mWs.cm ${ }^{-2}$ resultando em inativação média de 2,94 $\pm 0,51 \log$ para CT e $2,41 \pm 0,09 \log$ para E. coli.

Verificou-se também que o tempo de exposição de 90s não diferiu estatisticamente das médias obtidas no tempo de 60s, assim, em termos de custo-benefício e rapidez do processo, pode-se concluir que o tempo de $60 \mathrm{~s}$ se mostrou o mais adequado para a desinfecção do efluente em estudo.

Verificou-se que mesmo em reduzidos tempos de exposição é possível obter ótimos resultados de desinfecção, onde, para CT e E.coli as eficiências de redução com 30 segundos de exposição, dose média efetiva de $15,3 \mathrm{mWs} / \mathrm{cm}^{2}$ foram de 99,25 e $100 \%$ respectivamente.

Foram observadas eficiências médias de inativação de $E$. coli variando entre 0,58 a 2,41 unidades logarítmicas. Para a inativação de coliformes totais, as eficiências médias foram ainda superiores, algumas vezes aproximando-se de 3 unidades logarítmicas, para doses de radiação variando entre 15,3 e 92,7 mW.s.cm ${ }^{-2}$.

Como resultado, o efluente mostrou-se com potencialidade para reuso na agricultura. A fertirrigação apresenta-se como uma excelente alternativa, tendo em vista o atual cenário nacional, com tendência à escassez de recursos hídricos, pelos grandes volumes de efluente gerados na fabricação de papel, pela proximidade com extensas áreas de plantio de pinus e eucalipto, pela grande demanda hídrica e nutricional destes plantios, e, pela constante necessidade de melhoria no desempenho ambiental dentro do âmbito empresarial.

\section{REFERÊNCIAS}

APHA. American Public Health Association. Standard Methods for the Examination of Water and Wastewater. Washington: $22^{\text {nd }}$ edition. American Public Health Association, 2012.

CHERNICHARO, C.A.L. et al. Projeto PROSAB - Edital II tema 2 - PósTratamento de efluentes de reatores anaeróbios. Coordenador: Carlos Augusto Lemos Chernicharo, 2001, 544p.

DANIEL, L. A. (Coord.). Processos de desinfecção e desinfetantes alternativos na produção de água potável. Rio de Janeiro: RiMa, 2001.

DONAIRE, Patricia Pulcini Rosvald; GUIMARÃES, Jose Roberto; JARDIM, Wilson de Figueiredo. Eficiência de desinfecção de águas brutas utilizando radiação ultravioleta. In: Congresso Brasileiro de Engenharia Sanitária e Ambiental, 21., 2001, Campinas. I-015. São Paulo: Abes, 2001. 8p.

GONÇALVES， R. F.; FILHO, B. C.; CHERNICHARO, C. A. L.; LAPOLLI, F. R.; AISSE, M. M.; PIVELI, R. P. Desinfecção por radiação ultravioleta. In: GONÇALVES, R. F. Desinfecção de efluentes sanitários. PROSAB 3, Rio de Janeiro, p.209-276, 2003.

GUO, M.T.; HUANG, J.J.; HIU, H.; LIU, W.J. (2011) Growth and repair potential of three species of bacteria in reclaimed wastewater after UV disinfection. Biomedical and Environmental Sciences, v. 24, n. 4, p. 400-407. 
HESPANHOL, I. Potencial de reuso de água no Brasil: agricultura, indústria, municípios, recarga de aqüíferos. Revista Brasileira de Recursos Hídricos, Porto Alegre, v.7, n.4, p.75-95, 2002.

HIJNEN, W.A.; BEERENDONK, E.F.; MEDEMA, G.J. (2006) Inactivation credit of UV radiation for viruses, bacteria and protozoan (oo)cysts in water: a review. Water Research, v. 40, p. 3-22.

IBÁ - Indústria Brasileira de Árvores. Relatório anual 2016. Disponível em: http://iba.org/images/shared/Biblioteca/IBA_ RelatorioAnual2016_.pdf Acesso: 23/10/2017.

IBÁ - Indústria Brasileira de Árvores. Relatório anual 2017. Disponível em: http://iba.org/images/shared/Biblioteca/IBA_ RelatorioAnual2017.pdf Acesso: 23/10/2017.

JORDÃO, Eduardo Pacheco; PESSÔA, Constantino Arruda. Tratamento de Esgotos Domésticos. 7. ed. Rio de Janeiro: Abes, 2014.

KOIVUNEN, J.; HEINONEN-TANSKI, H. Inactivation of enteric microorganisms with chemical disinfectants, UV irradiation and combined chemical/UV treatments. Water Research. Finlândia, v. 39, p. 1519-1526, mar. 2005.

LAZAROVA, V.; SAVOYE, P.; JANEX, ML.; BLATCHLEY III, ER.; POMMEPUY, M. Advanced wastewater disinfection technologies: state of the art and perspectives. Water Science and Technology, v. 40, n. 45, p. 203-213, 1999.

METCALF E EDDY, INC. Wastewater engineering - treatment and reuse. 4 ed. Nova York: McGraw-Hill, 2003. 1819 p.

NATURALTEC. Tratamento de água e efluentes - Desinfecção Ultravioleta. 2010. Disponível em:
http://www.naturaltec.com.br/DesinfeccaoUltravioleta.html. Acesso: 28/06/2019.

NEVES, L.C (2014). Aplicação de ultrafiltração como pós-tratamento de efluente de lodo ativado de uma indústria de papel e celulose. 2014. Dissertação (Mestrado em Ciências Florestais) - Universidade Estadual do Centro-Oeste. 77p.

QUEK, P. H.; HU, J. Indicators for photoreactivation and dark repair studies following ultraviolet disinfection. Journal of Industrial Microbiology \& Biotechnology. Singapura, v. 35, p. 533-541, jan. 2008a.

QUEK, P. H.; HU, J. Influence of photoreactivating light intensity and incubation temperature on photoreactivation of Escherichia coli following LP and MP UV disinfection. Journal of Applied Microbiology. Singapura, v. 105, p. 124-133, 2008b.

REZENDE, A. A. P. Fertirrigação do Eucalipto com efluente tratado de fábrica de celulose kraft branqueada. $175 \mathrm{f}$. Tese (Doutorado) - Programa de Pós-Graduação em Engenharia Agrícola, Universidade Federal de Viçosa, Viçosa, 2003.

SMITH, C. T. et al. Land application of CTMP effluent in New Zealand: from research to practice. In: Third international conference on environmental fate and effects of pulp and paper mill effluents, Proceedings. Rotoura, New Zealand: CSIRO, 1997.

SOUZA, J. B.; VIDAL, C. M. S.; CAVALLINI, G. S.; QUARTAROLI, L.; MARCON, L. R. C. Avaliação do emprego da radiação ultravioleta na desinfecção de esgoto sanitário. Semina: Ciências Exatas e Tecnológicas, Londrina, v. 33, n. 2, p. 117126, jul./dez. 2012.

TEMPLETON, M.R.; HOFMANN, R.; ANDREWS, R.C. (2006) UV inactivation of

Vol. 18, N. 1 (2021) 
humic-coated bacteriophages MS2 and T4 in water. Journal of Environmental Engineering Science, v. 5, p. 537-543.

TCHOBANOGLOUS, G..; BURTON, F; STENSEL R. E. V. Wastewater Engineering: Treatment, Disposal, Reuse, Metcalf \& Eddy, Inc., 3a Ed., McGraw-Hill, New York, 1991.

THACKER, W. E. Silvicultural land application of wastewater and sludge from the pulp and paper industry. In: The Forest Alternative for Treatment and Utilization of Municipal Wastes, Washington D.C.: University of Washington Press, 1985b. p. 4154.

TSUTIYA, Milton Tomoyuki. Uso agrícola dos efluentes das lagoas de estabilização do Estado de São Paulo. In: Congresso Brasileiro de Engenharia Sanitária e Ambiental, 21., 2001, São Paulo. I-015. São Paulo: Abes, 2001. 16p.

USEPA, 2011. Drinking water treatment plant residuals. 2011. Disponível em: https://www.epa.gov/sites/production/files/20 1511/documents/dw-treatment-residu alsmgmt-tech-report-sept-2011.pdf. Acesso: 14/02/2019.

VON SPERLING, M., Introdução à qualidade das águas e ao tratamento de esgotos. 3 ed. Departamento de Engenharia Sanitária e Ambiental; UFMG, Belo Horizonte - MG, 2005.

Submissão: 01/10/2021.

Aceito: 12/03/2021.

Publicado: 12/03/2021. 